\title{
Innovation in the Mining Industry: Technological Trends and a Case Study of the Challenges of Disruptive Innovation
}

\author{
Felipe Sánchez ${ }^{1}$ (D) Philipp Hartlieb ${ }^{2}$ (i) \\ Received: 14 January 2020 / Accepted: 6 July 2020 / Published online: 23 July 2020 \\ (C) The Author(s) 2020
}

\begin{abstract}
Innovation plays a critical role in the mining industry as a tool to improve the efficiency of its processes, to reduce costs, but also to meet the increasing social and environmental concerns among communities and authorities. Technological progress has also been crucial to allow the exploitation of new deposits in more complex scenarios: lower ore grades, extreme weather conditions, deeper deposits, harder rock mass, and high-stress environments. This paper discusses the importance of innovation for the mining industry and describes the mechanisms by which it is carried out. It includes a review of the drivers and actors involved and current trends. The digital transformation process that the industry is going through is analyzed, along with other relevant trends that are likely to shape the mining of the future. Additionally, a case study is presented to illustrate the technical and economic implications of developing a disruptive innovation project.
\end{abstract}

Keywords Mining innovation $\cdot$ Mining technology $\cdot$ Digital transformation $\cdot$ Industry 4.0

\section{Introduction}

Over the past decades, the mining industry has had to face a challenging scenario for its operation. Improving productivity to overcome natural factors such as decreasing ore grades, deeper deposits, and harder rock mass, combined with an increasing environmental and social awareness, has boost the industry to constantly work to enhance their processes along the whole value chain. In this, innovation plays a crucial role by providing suitable solutions to surpass these difficulties, ensuring the continuity and sustainability of the mining activity.

There has been a historical debate whether mining is indeed an innovative industry or not. It is often perceived as a conservative sector, where innovation takes only a

Philipp Hartlieb

Philipp.Hartlieb@unileoben.ac.at

Felipe Sánchez

fsanchez@cochilco.cl

1 Department of Strategy and Policy Planning, Chilean Copper Commission, Santiago, Chile

2 Chair of Mining Engineering and Mineral Economics, Montanuniversität Leoben, Leoben, Austria secondary position in the concerns of companies. But at the same time, many argue that mining is more likely to be comparable with high-tech industries, considering that it utilizes vanguard technologies in its processes, such as automated or remote-controlled machinery, and advanced monitoring systems for the collection and analysis of large amounts of data [1].

Nowadays, many relevant actors of the industry claim that mining is going through the first stages of a deep changeover from the hand of digital transformation. It is said that this process could change how mining is done, passing from human-run operations to autonomous or semi-autonomous remote-controlled mines. Independent if fully automated operations are achieved in the near future or not, the digital transformation is already impacting the industry and will continue doing so.

This article aims to characterize the innovation environment in the mining industry, specifically:

- Importance of innovation for the mining industry: relation between labor productivity and innovation

- Dynamics of innovation in the industry: drivers and actors

- Current trends and future of the mining industry

It will contribute to improve the understanding of the dynamics and mechanisms involved in the innovation processes, 
along with analyzing the current status and expected future of the mining industry, in terms of technological advance.

The scope of this paper covers the mining industry in general and its entire value chain (exploration, extraction, processing, and smelting and refining). However, by the nature of the topic, artisanal and small-scale mining have been mostly excluded from the analysis, considering the historical low degree of technological specialization in this sector. Also, for the illustration and exemplification of certain points made in this document, a special focus has been put in the large-scale copper mining sector and the main copper producer countries.

\section{Innovation in the Mining Industry}

Cambridge Dictionary defines innovation as a new idea, method, design, or product, as well as its development or use [2]. In general, innovation can be understood as a process of change, through which a new idea or solution is applied in a good, service, or productive procedure to create value and meet new requirements from customers and higher safety or environmental standards, among other goals.

In this section, the importance of innovation for the mining industry is discussed. Firstly, the relation between innovation and labor productivity is examined. Then, a general view regarding the innovation dynamics within the industry is provided, exploring the main drivers and actors involved.

\subsection{Innovation and Labor Productivity}

A first approach to understand the relevance of innovation within the industry can be made through the analysis of labor productivity. Technological advances usually have an impact on the output, allowing larger production rates while maintaining a similar workforce, or directly reducing the needed personnel by the automation of processes. Nevertheless, changes in labor productivity of a mine may be caused by a series of other reasons. Natural factors, such as decreasing ore grade and deepening of deposits, mean that a larger amount of material in more complex situations must be removed to obtain the same final metallic output, thus impacting negatively on labor productivity, while, in an aggregated view (e.g., when analyzing the mining industry of an specific country), the discovery and exploitation of new and better deposits can also positively impact the overall labor productivity [3]. On the other hand, in a high-price mineral commodities scenario, companies are willing to compromise their costs in order to increase production (because it is profitable) and, therefore, reduce their labor productivity [4].

Several authors have analyzed the behavior of labor productivity in specific mining industries in an attempt to isolate the effect of innovation. Tilton et al. [5] first introduced the importance of innovation and new technologies in the growth of labor productivity while studying the decline and recovery of the US copper industry during the 1970s, 1980s, and 1990s. The authors attributed most of the labor productivity increase in this period to the incorporation of the solver extraction and electrowinning technology (SX-EW), along with the use of larger trucks, shovels and drills, in-pit mobile crushers and conveyor belt systems, computerized scheduling of trucks, and real-time process controls.

In a later study, more concrete evidence regarding the previously mentioned was provided [6]. Since the exploitation of new deposits can have an impact on the aggregated labor productivity, the authors built two scenarios to analyze this index between 1975 and 1995: one, considering only the mines operating at the beginning of the studied period, and therefore, excluding the effect of new mines, and two, the actual situation, including both old and new operations. In Fig. 1, the adjusted curve represents what labor productivity would have been if no new mines would have entered in operation in this period of time. As shown, adjusted and actual labor productivity resulted to be not so far different; thus, approximately $75 \%$ of the productivity growth in the US copper industry over those years came from productivity improvements at individual mines (i.e., innovation and technological advances), despite the exploitation of new deposits.

Under a similar methodology, the labor productivity growth in the Chilean copper industry during the 1978-1997 period was analyzed (Fig. 2) [7]. Their findings, though not as dramatic as in the US copper industry, showed that innovation and the introduction of new technologies were responsible for approximately a third of the productivity growth in the total period. Specifically, during the years prior to 1990 , this factor accounted for the total growth, while in the 1990s, the development of new world-class mines (e.g., Escondida) turned over the scenario. Nevertheless, these results were coherent

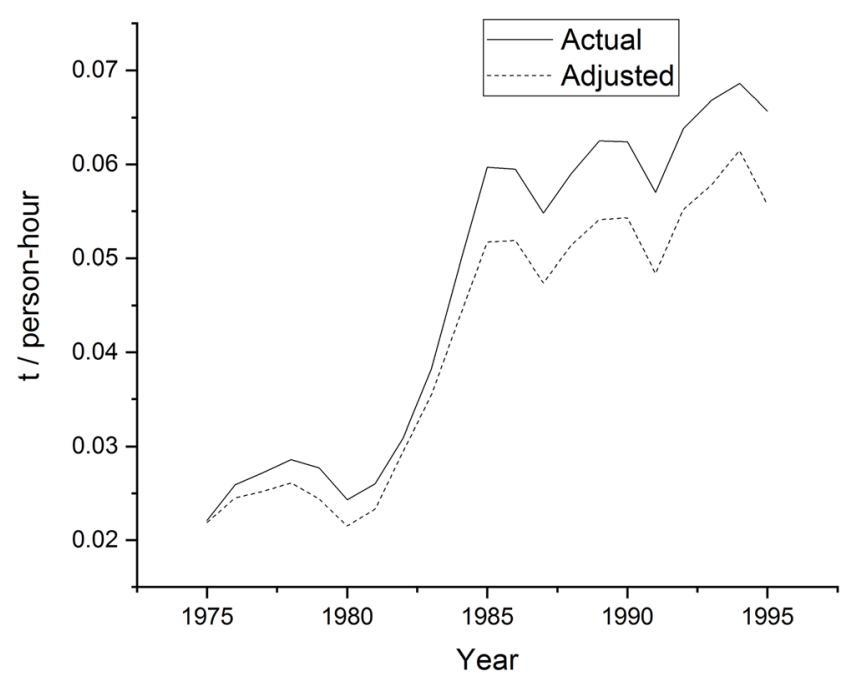

Fig. 1 Labor productivity in the US copper mining industry, actual and adjusted to exclude the effects of changing location of output , 19751995. Modified from [6] 


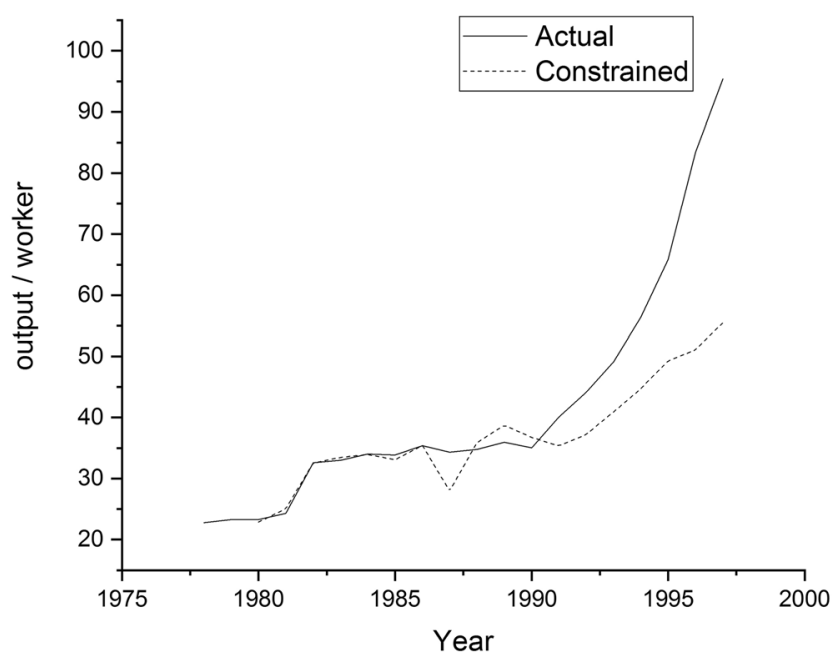

Fig. 2 Labor productivity for the Chilean copper industry, actual and constrained (or adjusted) assuming no change in the location of mine output 1978-1997 (tons of copper contained in mine output per copper company employee). Modified after [7]

with the findings of previous studies on the US copper industry, regarding the role of innovation in improving the competitiveness of the mining industry.

More recent research on the copper industry of Chile and Peru has presented additional supporting evidence that, though not the only factor, innovation, including the adoption of new technologies and managerial changes, remains as a key element for the improvement of labor productivity [3].

When looking at the following time period (late 1990s to early 2010s), the situation presents a dramatic change. From 2005 onward, the average labor productivity of Chilean mines suffered a sharp decline, as shown in Fig. 3. The same situation can be observed in other main mining countries, like Australia, Canada, and the USA (Fig. 4). Labor productivity in these countries started falling in the first years of the 2000s. This decline can be attributed to a combination of natural and

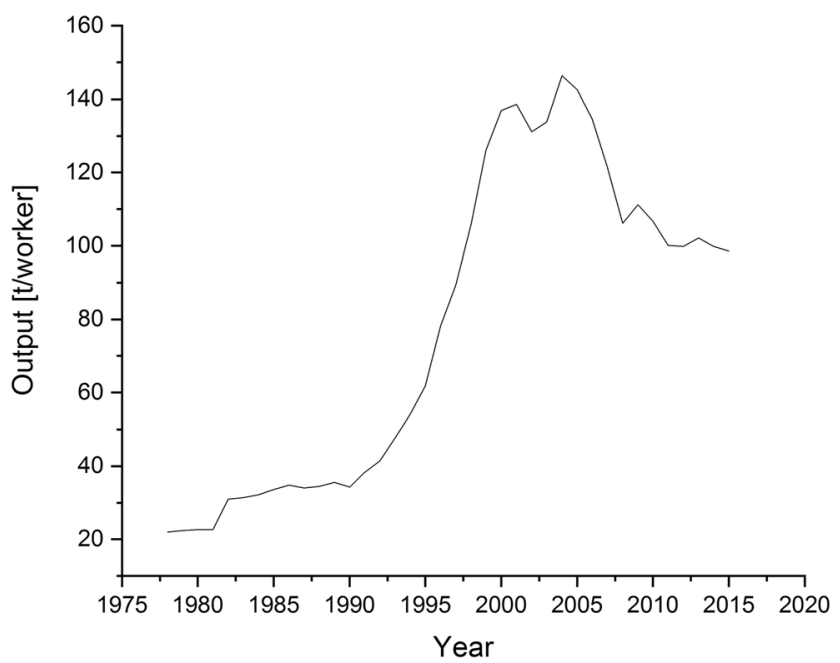

Fig. 3 Average labor productivity of Chilean mines for the period 19782015, measured as tons of mine production per worker. Modified after [4]

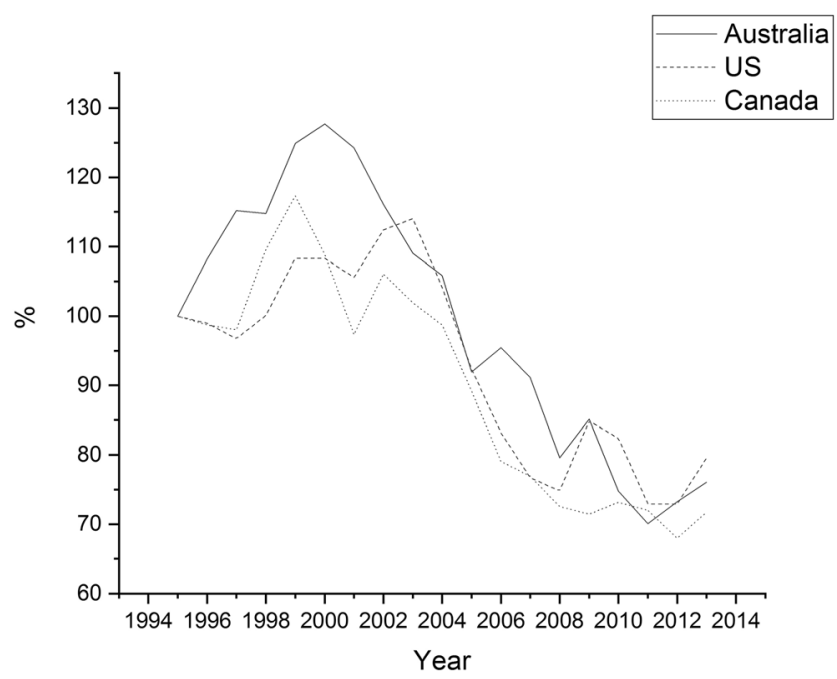

Fig. 4 Labor productivity of the mining sector of selected countries, for the period 1995-2013. Annual value presented as a percentage of labor productivity in 1995 (100\%). Modified after [4]

economic factors. On one side, while reserves are depleted, ore grades tend to decrease and the operation advances to deeper locations, increasing hauling distances, stripping ratio, and geotechnical difficulties, all of which have a negative impact on labor productivity. On the other side, in a period of high mineral commodity prices, like the one that the industry went through during the second half of the 2000s and the beginning of the following decade, mining companies will favor production growth despite productivity [4].

As presented, labor productivity is affected by a series of factors, mainly by natural characteristics of mineral deposits, market conditions, and innovation. While in periods of labor productivity growth it has been possible to isolate the positive effect of innovation, during declining cycles, this task turns more complicated. However, the fall in these periods is attributed mainly to natural and economic factors. In the meantime, innovation remains crucial to maintain the competitiveness of the industry, to the extent possible, providing the methods and tools to overcome the natural challenges faced by modern mines and exploit new and more complex deposits. In other words, while declining labor productivity may be inevitable during certain periods of time, the development and adoption of new technologies, along with innovation at a managerial level, are essential to maintain mining's competitiveness through the different cycles.

\subsection{Drivers for Innovation and Actors}

As discussed in the previous section, innovation constitutes an important factor affecting the productivity of mining operations. Examples of technologies developed to improve the efficiency of processes, reduce costs, and in consequence enhance productivity are easily found. Hydrometallurgical production method SX-EW has been identified as a major 
contributor for productivity growth in the US copper industry over the last decades of the twentieth century [6]. Likewise, continuous mining equipment in underground coal mining, along with draglines and bucket wheel excavators in surface coal mining, were key advances to reach new levels of productivity in coal production. In smelting processes, the development of flash, and, more recently, bottom blowing furnaces, has had a great impact in reducing energy consumption and OPEX.

Besides boosting productivity, through innovation, it has been possible to unlock the potential of deposits that were technically infeasible to exploit by traditional methods. For example, preconditioning of the rock mass through hydraulic fracturing, confined blasting, or a mix of both has allowed the exploitation of deeper ore bodies, in high-stress environments.

Addressing safety and environmental concerns has been also a major driver for innovation. Over the recent decades, focus has been put on removing workers from critical activities through the automation of processes and the use of autonomous and semi-autonomous (remote-controlled) equipment.

Meeting more rigorous environmental regulations and attending the concerns of local communities are minimal requirements for maintaining the social license to operate. Therefore, innovation has been also aimed at developing cleaner and more environmentally friendly solutions in the whole value chain of the business, and not only to improve the efficiency and reliability of its processes [8]. Examples of these are the new tailings disposal methods that have been implemented to reduce the impact of mining on the environment, such as the thickened and paste tailings disposal. These methods improve water efficiency in their processes, reduce the requirement of surface for their disposition, and minimize risks of collapse, among other advantages over traditional methods.

Regardless, extractive firms have historically shown low levels of expenditure in research and development (R\&D), often perceived as the main innovation-related index [8]. During the decades of the 1990s and 2000s, R\&D intensity of relevant mining and mineral companies, understood as the $R \& D$ expenditure as a percentage of total revenues, was on average only approximately $0.5 \%$ [9].

Figure 5 shows the average $R \& D$ intensity for some of the largest mining companies, as revenue level refers, during the 2011-2018 period. Though presenting variation during the period, on average, this index has remained around $0.4 \%$. These levels of R\&D intensity are considerably low compared with other industries. For example, in 2015, pharmaceuticals and information and communications technology (ICT) equipment, the most R\&D-intensive industries, reached levels of $25.1 \%$ and $24.7 \%$, respectively. Moreover, the average R\&D intensity in 2015, across all industries in OECD countries, was $5 \%$, more than ten times the level of the selected mining companies [10].'

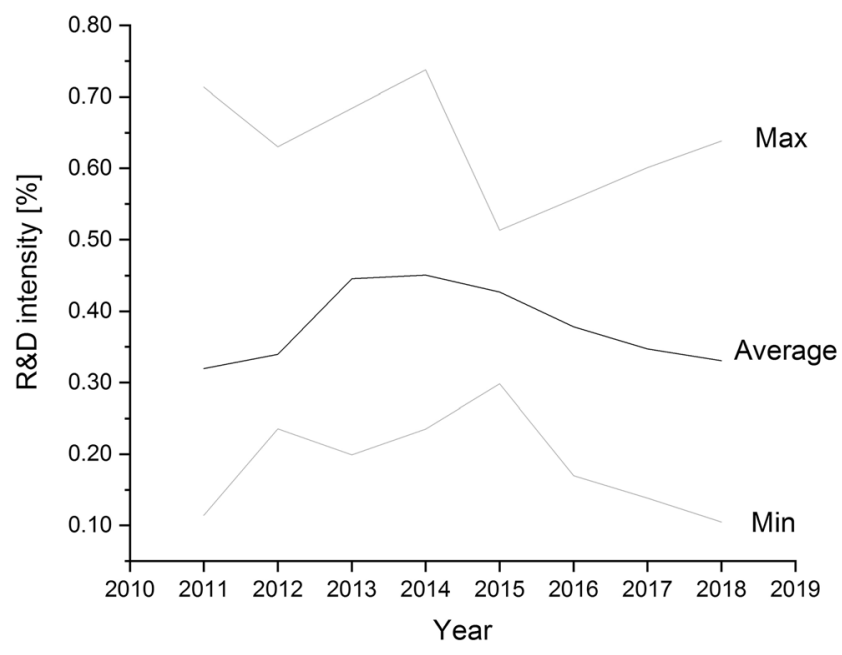

Fig. 5 R\&D intensity of five of the largest mining companies, based on 2018 revenues (companies selected according to availability of information i.e. $R \& D$ expenditure informed in annual reports, individualized and separated from exploration expenses). R\&D intensity calculated as a percentage of total annual revenues for the 2011-2018 period (in the case of Zijin Mining, R\&D intensity was calculated as a percentage of total operating income, according to data reported by the company). Data retrieved from annual reporting of companies Anglo American (available in: https://www.angloamerican.com/ investors/annual-reporting), China Shenhua Energy Company (available in: http://www.csec.com/shenhuaChinaEn/1382683238772/dqbg.shtml), Codelco (available in: https://www.codelco.com/prontus_codelco/site/ edic/base/port/memorias.html), Rio Tinto (available in: https://www. riotinto.com/investors/results-and-reports-2146.aspx), and Zijin Mining (available in: http://www.zijinmining.com/investors/Annual-Reports. jsp).

Measuring the level of innovativeness of an industry by only examining R\&D intensity, however, can lead to misinterpretation. Some authors argue that R\&D expenditure fails to consider other activities that could be related to innovation efforts, such as engineering development, plant experimentation, and exploration of new markets. Also, R\&D expenditure in general does not include mineral exploration expenses [8]. While these arguments may be reasonable, it is necessary to analyze in more detail how and by whom innovation is done in mining.

Whereas in the past mining companies would have tended to develop technology solutions in-house, over the last decades of the twentieth century the tendency changed. Economies of scale from using larger loading and hauling equipment had an important impact in improving productivity and reducing costs. Yet, these solutions came from equipment manufacturers, not from mining companies [1]. This is how outsourcing became a tendency among large producer firms, resulting in higher degrees of vertical disintegration [11]. Companies would focus on their core business, while relying on suppliers for the development of technological solutions, therefore avoiding the risks associated with the large investments involved. At the same time, in many cases, suppliers of such are also subcontractors for mining companies, handling 
construction and mining activities in projects and operations. These include the development of methods, techniques, and technologies to accomplish these tasks and therefore liberating their clients, the mining companies, from the technological concerns.

Leading technology suppliers, such as Sandvik, Epiroc, and Caterpillar, among others, have not only focused in the development of new equipment according to the technological and sustainability trends (currently, on automation and electromobility), but they have also put effort in the development of the proper digital systems for the operation and coordination of these machinery within the operations (e.g., AutoMine ${ }^{\circledR}$ from Sandvik).

Though large global suppliers are important actors for the development of new technologies, the outsourcing tendency previously mentioned has also opened the opportunity for the emergence of local knowledge intensive mining suppliers. These firms hold specific local knowledge that allows them to provide customized solutions for mining companies in niches that cannot be covered by the standardized products offered by large global suppliers [12].

Also, this outsourcing trend has promoted the creation of collaboration initiatives between large mining companies, local suppliers, and governmental and academic institutions for the development of technological solutions. Instances like these can be found in Australia, Chile, and Brazil [11]. In Chile, for example, the World-Class Supplier Program, a public-private partnership between the mining companies BHP, Codelco, and Antofagasta Minerals; Fundación Chile and other governmental institutions; and more than 75 local suppliers has already developed over a hundred innovation initiatives since it was launched in 2009. Though the program has had a positive impact in the development of the knowledge-intensive mining supplier sector in Chile, certain challenges need to be faced to bring this sector to the next level of progress. Among these challenges, it is necessary to escalate the program, promoting high-impact and long-term innovation projects, despite the usual incremental technological solutions developed until now [13].

Unlike most mining companies, the supplier sector holds in high priority the innovation agenda. A survey conducted on 432 firms from the Mining Equipment, Technology and Services (METS) sector in Australia, in 2015, revealed that for $63 \%$ of these companies innovation was core to their business strategy, driven mainly by a customer-focused vision, the necessity of staying ahead of the competition and direct solutions requirements from their customers [14].

A similar view is shared by the mining supplier sector in Chile. One hundred five of these companies were surveyed in 2019, revealing a high level of innovation-aimed expenditure. On average, they reported innovation expenses for $14.3 \%$ of 2018 revenues, reaching levels of $28.7 \%$ and $22.3 \%$ in the medium- and small-scale suppliers, respectively. Likewise, their innovation projects were driven mainly by direct solutions requirements from their customers, the necessity of staying ahead of the competition and by having innovation as core to their business strategy [15].

Besides the dynamics involved in the development of technologies, either by mining companies themselves or their suppliers, the mining industry is also recognized for its capacity to adopt technologies from other industries. ICTs have facilitated the introduction of important improvements in exploration techniques, mining, and processing. Simulations, sensor systems, automation and remote-controlled operations are some examples [8].

Nowadays, ICTs offer a new level of technological advance from the hand of digital transformation. The extractive industry finds itself in the early stages of adopting these new technologies. The full potential of their applicability for mining processes is yet to be unlocked. The implications of the current trends of Industry 4.0 for the mining industry are discussed and analyzed in the following section.

\section{Current Trends and Mining of the Future}

Defining a future view for an industry is not a simple task. Nowadays, the world is changing faster than ever before. New technologies are developed every day, impacting the way people live. The phrase "we live in a different world than the one where our parents grew up" does not completely cover the reality of the past few decades. For example, in current days, most people would not conceive their lives without their smartphones, and even though the first ones were commercialized in 1992, the massification of these devices came only a little more than a decade ago (e.g., the first iPhone was developed in 2007).

Nevertheless, in the case of the mining industry, it is possible to identify certain trends that can be of help to outline this future scenario. First and most evident, it is the major technological shift occurring across all industries: the so-called Fourth Industrial Revolution, or simply Industry 4.0, as the transition to the digital era. Then, social and environmental concerns are already compelling mining to look for safer, more efficient, and sustainable ways of conducting the business. Reduction of energy and water consumption, lower emissions, and waste generation are all factors that will be in the core of the "mine of the future."

\subsection{Digital Transformation in Mining}

Over recent history and since the beginning of industrialization, several changes in production paradigms have taken place, promoted by the surge and application of novel technologies. As shown in Fig. 6, the world has already seen three paradigm shifts, better known as industrial revolutions. 


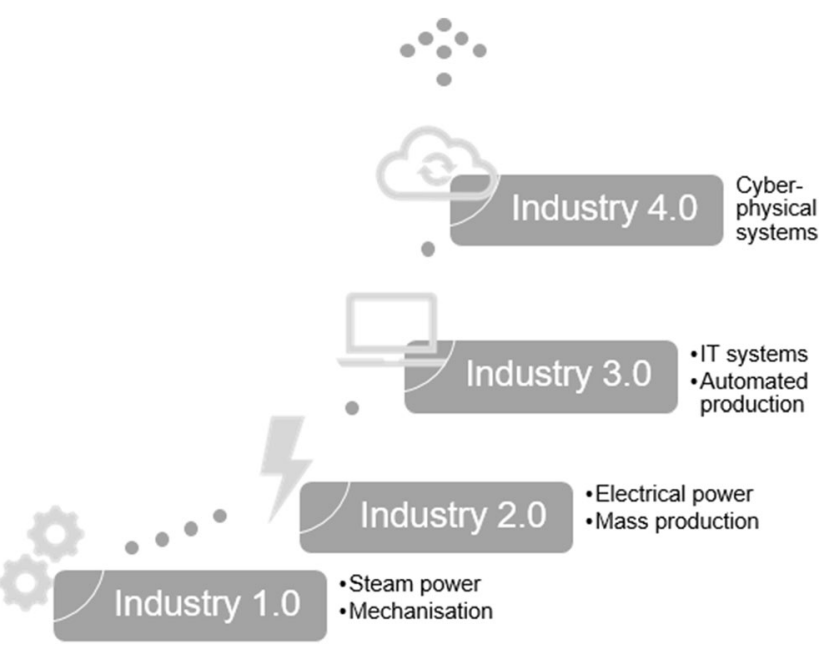

Fig. 6 Industrial revolutions

Currently, a new transformation is in progress from the hand of cyber-physical systems and a set of new technology developments, e.g., automation, internet of things, and analytics $[16,17]$.

The Fourth Industrial Revolution brings a new concept of industry, also called Industry 4.0. This concept is based on an advanced digitization of production processes and the combination of internet-oriented technologies, allowing the connection between smart sensors, machines, and IT systems across the value chain. The implementation of these cyber-physical systems should bring a series of benefits, such as productivity increase by the automation of production and decisionmaking processes, reduction of waste, improvement of equipment utilization, and maintenance costs reduction. However, Industry 4.0 is not only about the adoption of new technologies, but it will also demand organizational changes, specialized knowledge, and expertise [16, 17].

To achieve the scenario set by Industry 4.0 , companies from all sectors, though at different speeds, are implementing the necessary changes at a technological and organization level. These changes constitute the process of digital transformation.

\subsubsection{What Is Digital Transformation?}

Though the term digital transformation (DT) has been extensively used in recent years, mainly to describe the adaptation process of organizations to new digital technologies, there is not a unique definition for it. On the contrary, there are many. Acknowledging this situation, and after an exhaustive review of DT-related literature, [18] offers the following definition: "a process that aims to improve an entity by triggering significant changes to its properties through combinations of information, computing, communication, and connectivity technologies."
The reason for the existence of various acceptations for DT may lie in the differences among industries: each sector operates in particular ways; therefore, each digital technology will have a different impact, depending on the industrial sector adopting it.

The specific information, computing, communication, and connectivity technologies involved in DT also vary from one industry to another. In the case of mining, however, it is possible to identify a set of tools that will and are already affecting the processes not only at the mine site but across the operational and corporate units within a firm.

\subsubsection{Key Technologies in the Digital Mine}

DT is a transversal process of change across the complete value chain of the mining industry, from the exploration to the production of final products, their commercialization, and even the closure of operation sites. Experts, companies, and government agencies have been discussing how the "digital mine" should look like while advancing forward in the DT process. Figure 7 shows how modern digital technologies are and will keep affecting the different areas of the business.

As shown, novel technologies are producing operational changes across the value chain, and their use is not necessarily exclusive for a specific activity. For example, intelligent operation centers are being implemented for both extraction and processing operations. Likewise, augmented and virtual reality, along with digital twinning, are tools that will enhance the design and construction of mining projects ("Establish" in Fig. 7), and the extraction and processing operations.

While the view of the "digital mine" may vary among firms and organizations, it is possible to define a set of core

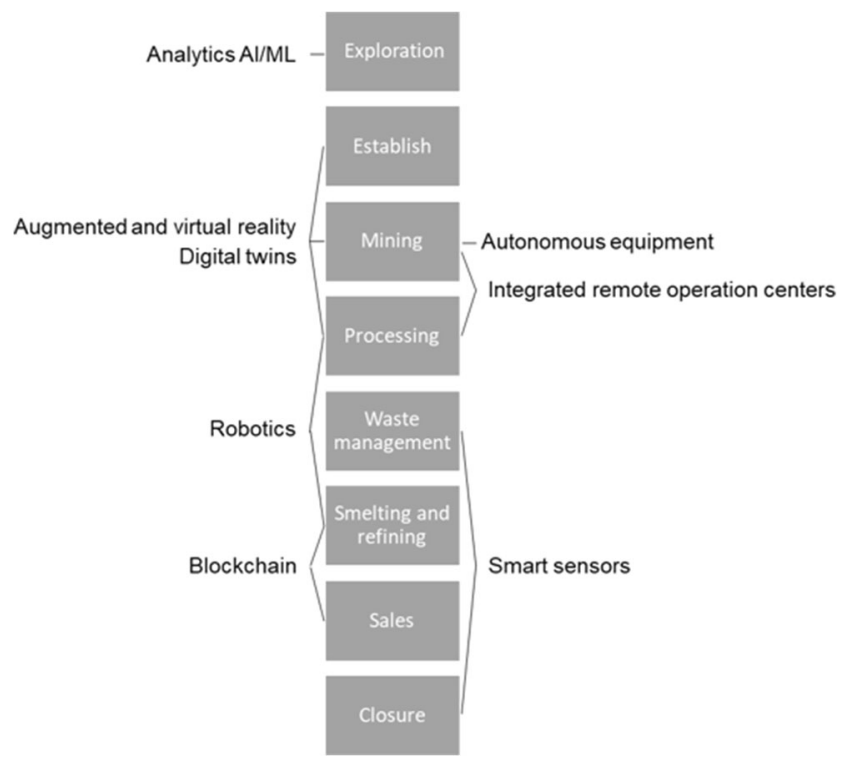

Fig. 7 DT technologies in the different stages of the mining value chain. Based on [19, 20] 
technologies that represent the pillars of the DT in the mining industry [19-27]. These key elements are described below.

Automation, Robotics, and Remote Operation These technologies might hold the highest level of implementation among the tools offered by DT. The first and more clear benefit of the automation of processes, use of robots in critical activities, and remote operation centers (ROC) is the improving of safety, by reducing the number of operators required in hazardous sites [25].

ROCs can also significantly reduce OPEX and CAPEX of mining operations. Since less workforce is needed at the mine site, fewer or none supporting infrastructure is required, such as housing installations, hospitals, or schools. Also, other expenses are reduced, such as transportation of operators. The impact on costs is larger as the location of the mine is more remote, distant, and isolated [25].

The use of autonomous equipment, such as hauling trucks, LHDs, and drillers, is expanding rapidly. For example, global equipment manufacturer Caterpillar has already provided more than 239 autonomous trucks for large-scale mining operations in Australia, Brazil, Canada, and the USA [28].

Similarly, Komatsu holds a total fleet of 141 autonomous trucks distributed in Australia, Canada, Chile, Japan, and the USA. In Chile, these vehicles operate in Codelco's mine Gabriela Mistral. Over the 10 years of operation of the mine, the use of autonomous trucks has allowed a significant collision risk reduction and high levels of productivity and tires performance [29].

By February 2020, a total of 459 autonomous haul trucks were accounted as active in mining operations around the world [30]. Though these equipment still represent less than $1 \%$ compared with the total of manual trucks currently operating, ${ }^{1}$ they are characterized as high year-to-year growth: 32\% in the 2019-2020 period and higher rates are expected for the next years, from the hand of significant investments made by major companies such as BHP, Fortescue Metals Group, Rio Tinto, and Hancock Prospecting in Australia and Suncor Energy and Canadian Natural resources in Canada.

In general terms, besides the benefits in safety, autonomous equipment enhance productivity and reduce operational costs, by increasing equipment's utilization (due to the continuous operation), reducing variability in the production outcome, and improving tires and components performances [20, 29].

Internet of Things (IoT), Smart Sensors/Real-Time Data Capture IoT is understood as a network of physical

\footnotetext{
${ }^{1}$ According to data from The Parker Bay Company. Available in: https:// parkerbaymining.com/mining-equipment/mining-trucks.htm
}

objects, such as sensors, equipment, machinery, and other sources of data. The elements connected to this network can then interact, exchange information, and act in a coordinated way [31]. Thanks to advances in IoT technology, nowadays, it is possible to establish low-cost networks. Additionally, the development of smart sensors allows real-time capture of data from machines and equipment across the operation. This generation of data is the base to conduct an integrated planning and control, considering the different units within the operation, and support the decision-making process [20].

Analytics, Artificial Intelligence (AI)/Machine Learning (ML) Due to the digitization of processes, advances in IoT, and real-time data capture, mining operations have enormous amounts of data available regarding production, processes, and performance of machines, among others. Through advanced analytics methods, it is possible to transform this information allowing its use for a better planning of activities and to support fast and effective decision-making processes for the operation. Predictive models can also be developed to enhance maintenance of equipment, therefore improving productivity [21].

$\mathrm{AI} / \mathrm{ML}$ methods are also being applied for mineral prospecting [32-34]. It is expected that these methods will optimize the prospection and exploration activities, reducing costs and improving their accuracy.

Digital Twinning The concept of digital twinning refers to the construction of a digital model of the physical operation. This is possible using the geological and engineering information of the site, but more importantly, thanks to the real-time data generated from the sensors connected across the operation. With the digital twin of the mine, it is possible to perform simulations and predict potential failures or downturns in equipment performance. Thus, the digital twin constitutes a useful tool to improve operational planning and reduce operational costs, by avoiding unexpected interruption in production processes and optimizing the maintenance of equipment $[20,21]$.

\subsubsection{Current Status of DT in the Mining Industry}

In its study of 2017, the World Economic Forum and Accenture estimated a potential benefit for the mining industry, as a consequence of DT, of US\$ 190 billion over the period 2016-2025, equivalent to approximately $9 \%$ of the industry's profit [26]. Correspondingly, in the USA, the mining industry has been included among the group of sectors with potential to increase productivity from the further digitization of its assets, customer relations processes, and transformations in its workforce [35]. These expectations are aligned with the results of a survey conducted by Accenture in 2014 
among executives from 151 mining companies around the world. In this, $85 \%$ of the surveyed executives reported that their companies were strongly supporting internal DT initiatives and $90 \%$ that the DT programs were already elevated into strategies and high-level decision-making [25].

However, the level of overall digitization of mining is still low, when compared with other industries. By 2014, though DT was mentioned in six out of ten of some of the largest (by market value) global mining companies' annual reports, ${ }^{2}$ qualitative benefits from DT were reported only by three of them and only one presented actual quantitative gains [25]. This confirms that, though DT has claimed a relevant position among mining companies' concerns, on average, the industry is still in the early stages of this transformation, and most of the potential benefits are still to be unlocked.

Correspondingly, a survey conducted on 105 companies from the mining supplier sector in Chile in 2019 revealed that $59 \%$ of them perceived a medium level of interest from the mining companies to incorporate DT-related technologies and $32 \%$ a low level of interest. Only $9 \%$ of the surveyed firms perceived a high level of interest from mining companies to incorporate these technologies in their operations (Fig. 8). Regardless, most of these suppliers are already developing or will develop in the next 5 years products or services incorporating technologies 4.0 , being remotization, automation, smart sensors, and analytics the most frequent ones [15].

In general terms, though DT is frequently mentioned as one of the main concerns among most large-scale mining companies, which over the years has generated great expectations regarding its benefits, the overall level of digitization of the industry remains low. Nevertheless, there are several cases of mining operations where a high level of digitization and automation of its processes has been achieved. LKAB's iron ore mines, Kiruna and Malmberget, located in northern Sweden, are operated under a combination of remote-controlled and fully automated equipment for drilling, blasting, and hauling processes. Moreover, full automation and electrification are core elements in the future plans for deeper levels, for which development KLAB has been working in close collaboration with high-tech companies, such as ABB, Epiroc, and the Volvo group [36]. Similarly, the Syama underground gold mine in Mali, owned by Resolute, constitutes the first fully automated mine, incorporating an automated haulage system, automated rehandle level, and mine digitization [37, 38].

Likewise, some technologies present a greater level of adoption across the mining industry than others. For example, autonomous and semi-autonomous equipment, such as trucks, LHDs, drills, and trains, started to be tested more than a

\footnotetext{
${ }^{2}$ Companies in this analysis: Rio Tinto, BHP, Vale, Glencore, Anglo American, Codelco, Fortescue Metals Group, OCP Group, FreeportMcMoRan, and Nornickel
}

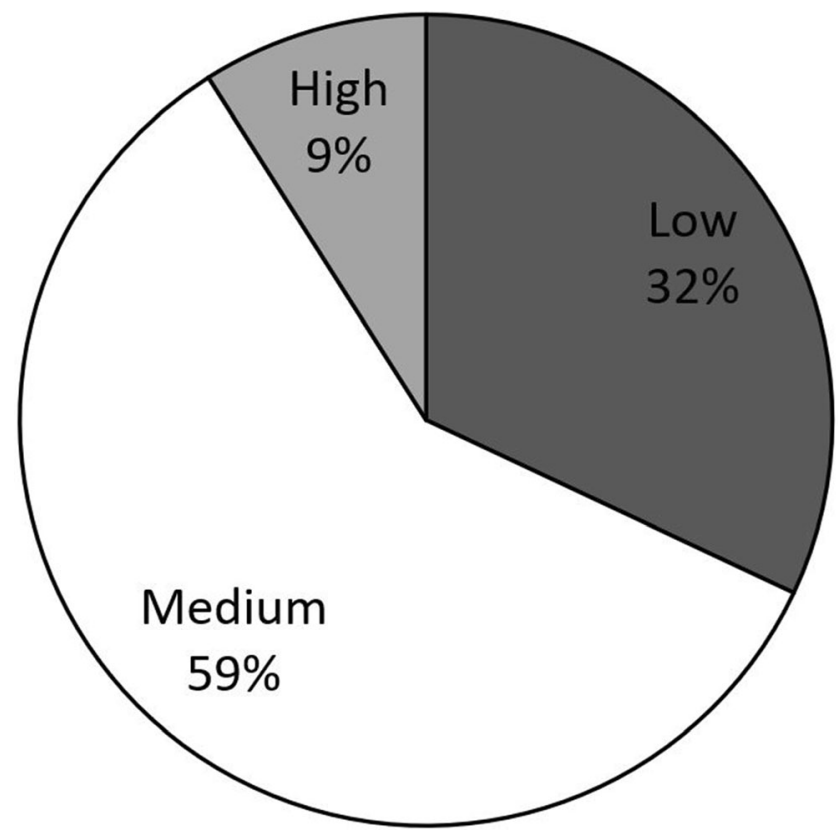

Fig. 8 Level of interest of mining companies in Chile in 2019, perceived by the mining supplier sector, regarding the incorporation of DT-related technologies in their operations. Based on [15]

decade ago (in some cases, even before); some have been successfully operating for several years now and are rapidly spreading $[28,29,39]$. In the same way, many companies have implemented ROCs to control their operations remotely. In Chile, for example, Codelco has a ROC for its mine Ministro Hales and it is developing centers for three more of its divisions [40]. BHP has also implemented its Centre of Integrated Operations (CIO) in Santiago, Chile, from which it will coordinate all its operations in the region.

Smart sensors and monitoring systems are also already generating large amounts of data. However, the wide and successful application of advanced analytics to support and gradually automate the operational decision-making processes is still to come. Today, its use remains mainly in the construction of predictive models for maintenance purposes and the visualization of data to support human decision-making.

\subsubsection{Challenges in the Implementation of DT}

For the period 2019-2020, the "digital effectiveness" has been identified as the second most relevant risk for the mining industry [41]. It highlights the importance of advancing in digitization, as a necessity for companies to remain competitive. The main risk lies then on the fact that DT is often perceived as a task exclusive of the information technology (IT) area. Nonetheless, to achieve a truly effective and valuecreative transformation, it must be carried out as a joint task across the organization, with a shared view of the business 
goals and a strong commitment from the top management. Otherwise, DT initiatives will remain as isolated IT projects, with no significant benefits considering the investments involved [22, 23, 41].

Ensuring the convergence of IT and OT (operational technology) is also key for a successful DT. These areas have traditionally worked by different paths: IT closely to corporate and support systems, while OT running core processes at the operation site. However, the automation of processes requires an integrated IT/OT management [20].

DT is a process of change that goes beyond technology. As mentioned in the first paragraph of this section, it requires coordination across the whole company. But it is also important to understand what this transformation will mean at an organizational level [22]. Structures will suffer changes by the automation of processes and introduction of new technologies and methods. For example, a recent study revealed that around $80 \%$ of the current labor competences in the mining sector in Chile will potentially change in the middle and long term as a consequence of the technological progress. Even more, at least $40 \%$ of them have a high probability of being replaced by automated processes [42]. This situation must be considered and evaluated. The new structures must be designed in advance and action must be taken to prepare the employees for these new arrangements. New knowledge and skills will be required, so the firms should also invest in the proper training programs to face DT.

Finally, in an increasing digital environment, a special focus must be put in cybersecurity. DT brings a wider connectivity among equipment and sensors but also between different business units. The company could then be exposed to greater risks of security breaches. For this reason, cybersecurity constitutes a fundamental element in DT [20,25]. In fact, [41] also classified this issue as the fourth most important risk for the mining industry in 2019-2020. To overcome this risk, a solid "cybersecurity culture" must be promoted in every level of the organization, incorporating new security-related practices in the daily responsibilities of the employees, along with the measurement of relevant KPIs and a periodical revision of the adopted strategies to evaluate their effectiveness and generate improvements, if necessary [41].

\subsection{Mining beyond DT}

In parallel with the technological wave brought by the digital transformation, a series of other trends have been gaining relevance in the mining industry over recent years. Driven by safety and environmental concerns, cost reduction, enhancement of efficiency, and productivity in the operation, or a mix of these motives, these trends are complementary to the technologies 4.0 and offer an idea of the future paths that mining might follow.

\subsubsection{Electromobility}

Electromobility, as the development and use of electricpowered vehicles, is a technological trend across industries. From personal-use cars and public transportation vehicles, to heavy machinery, electromobility offers an economical and more environmentally friendly alternative to the use of fossil fuels.

Mining is especially affected by this paradigm change. Most mobile equipment in mining operations has been historically powered by internal combustion engines (ICEs), using diesel fuel. While the impact of the negative aspects of these engines might be bearable in open pit operations, in underground mines, where ventilation can account for up to 25 $40 \%$ of the total energy costs, the situation is different [43]. Diesel ICEs emit exhaust gases containing a series of pollutants, such as unburned hydrocarbons (HC), carbon monoxide (CO), nitrogen oxides (NOx), and diesel particulate matter (DPM). Additionally, a large amount of heat is also produced. All these elements increase the demand for fresh air flow in order to ensure a proper working environment for operators and equipment, having a significant impact on costs [44].

Moreover, due to the increasing environmental and safety awareness in the industry, regulations regarding the admissible levels of pollutants have become stricter in the past decades and are likely to become even stricter in the future. At the same time, after exhausting shallow deposits, mining is moving to deeper locations, aggravating the temperature conditions [45].

Even though some methods to provide electric power have been used for a long time already (e.g., trolley assist), today there are more incentives to look for electric-powered alternatives to replace the mobile equipment that have been predominantly running with diesel ICEs, like LHDs and haul trucks. According to the method used to supply the motor with electric energy, this equipment can be classified into five categories [45]:

- Trolley powered

- Battery powered

- Cable powered

- Hybrid ICE/electric equipment

- Hydrogen fuel cell powered

In Table 1, a summary of the differences among dieselpowered equipment and the categories mentioned of electricpowered equipment, according to key operational, environmental, and economic parameters, is presented.

In general terms, the main advantages of electric-powered over diesel-powered equipment are higher energy efficiency, higher service life (and, therefore, lower fleet requirements along the life of the mine), lower maintenance requirements, reduced generation of pollutants, heat and noise, and overall 
Table 1 Comparison between diesel-powered and electricpowered equipment. Compiled from [44-46]

\begin{tabular}{lllllll}
\hline Parameter & Diesel & Battery & Cable & Trolley & Hybrid & Hydrogen \\
\hline Flexibility & High & High & Low & Low & High & High \\
Autonomy & High & Low & High & High & Medium & High \\
Specific energy & High & Low & High & High & Medium & High \\
Energy efficiency & Low & High & High & High & High & High \\
Overload capacity & Low & High & High & High & High & High \\
Additional infrastructure & No & No & Yes & Yes & No & Yes \\
CAPEX & Low & High & High & High & High & High \\
OPEX & High & Low & Low & Low & Low & Low \\
Maintenance requirements & High & Low & High & Low & Low & Low \\
Service life & Low & High & High & High & High & High \\
Refueling/recharging & Fast & Slow & None & Fast & Slow & Slow \\
Pollutants emission & High & None & None & Low & Low & Low \\
Heat generation & High & Low & Low & Low & Low & Low \\
Noise and vibration & High & Low & Low & Low & Low & Low \\
\hline
\end{tabular}

lower operating costs. The lower ventilation requirements can also have an impact on the CAPEX of the mining project, by reducing the size of ventilation adits and fans. On the downside, electric-powered equipment usually presents higher CAPEX and, depending on the type, can present some other disadvantages (Table 1). Also, the specific conditions of the operation can affect the preference for one specific technology, e.g., open pit vs. underground, haulage distances, deepness and rock temperature, regulations of the country, and diesel and electricity prices. For these reasons, an integral techno-economic evaluation must be conducted in each case.

Nevertheless, a lot of effort is currently being put in R\&D regarding electric-powered equipment, especially battery and hydrogen fuel cell-powered. These show the greater potential to replace diesel equipment, due to their high flexibility, besides the safety and environmental advantages already mentioned [43].

Main mining equipment manufacturers have already developed several models of battery-powered vehicles. The Epiroc's "zero-emission fleet" for underground operations includes the Minetruck MT42 Battery (articulated low-profile truck), Boomer E2 Battery (drill rig), and the Scooptram ST14 Battery (LHD) [47]. In the meantime, Caterpillar continues to develop its R1700 XE battery-powered LHD [48] and Sandvik works on its LH514BE battery-assisted LHD (as a combination of battery and tethered cable) [49].

Though the transition to electric mining equipment has been relatively slow, it is difficult to think of a mining industry of the future still depending on fossil fuels. The shift to cleaner sources of energy is global: industries and governments across the world are implementing renewable energy sources strategies and policies, regulations are becoming stricter and social scrutiny harder. Electromobility has arrived to stay and the mining industry is not excluded from its influence.

\subsubsection{Invisible Zero-Waste Mining}

The concept of a mining with no impact on the surface is not new. Underground operations have been using their waste material to backfill open cavities left after ore extraction, mainly for stability reasons and as a mean to reduce haulage costs. At the same time, this practice reduces subsidence effect and, therefore, the impact on the surface above the underground mine. However, it is not possible to use all the waste extracted due to interference with the operation (e.g., during early development stages). Also, not every mining method allows backfilling application (e.g., caving operations). Therefore, it is certain that impact on the surface can be significantly reduced, but most of the time it is unavoidable.

In this regard, in situ leaching (ISL), also referred to as in situ recovery (ISR), constitutes an alternative that minimizes the effect on surface and generates practically zero waste. This method is understood as the in-place leaching of the ore, recovery of the enriched solutions, and their transportation to the surface for further processing.

ISL has been mainly applied in uranium mining (since it was first introduced in 1959 in the U.S.). There is also a record of successful cases of ISL applied in copper and gold deposits, though in relatively small scales. Besides typical characteristics of deposits (e.g., shape, dimensions, mineralization, grade distribution), the most critical factors restricting its applicability are permeability, hydrogeological conditions in site, and the possibility of achieving selective leachability of the ore body [50]. Containment of the leaching solutions within the zone of interest to prevent the contamination of groundwater might be the greatest environmental risk regarding ISL [51].

From an economic point of view, ISL presents obvious advantages over traditional mining methods. Energy consumption is reduced, thus lower OPEX needs to be met. ISL 
also requires lower CAPEX for infrastructure and mine developments. Additionally, this mining method admits a high production flexibility and can be developed as a modular project, if desired [50].

Future widespread application of ISL depends greatly on the technological advance regarding permeability enhancement and hydrogeological management. Findings in preconditioning techniques used in caving operations are likely to be adapted and applied in ISL mining for permeability improvement. Pilot tests of in situ bioleaching have shown that it is possible to enhance permeability within the orebody after the application of conditioning methods, such as hydraulic fracturing and water pressure blasting [52], whereas the use of barriers, such as the gel barriers widely used in the oil and gas industry to control the flow of sweep and production, are also potentially applicable for this mining method as a tool for proper leaching solutions containment [53]. For these reasons, R\&D efforts should be mainly aimed at the adaptation and improvement of existing technologies.

Besides environmental benefits of this method, if the restrictions mentioned can be overcome, ISL opens the possibility to exploit very deep low-grade deposits, currently uneconomic or technically infeasible to mine.

\subsubsection{Continuous Mining}

Continuous extraction and material handling systems have been used for many years in the coal mining industry. In surface operations, this has been carried out combining the action of bucket wheels excavators for the extraction and conveyor belt systems for the transport of coal and waste. Meanwhile, underground methods such as longwall mining and room and pillar (by using continuous miner equipment) have also offered continuous flows of material. However, due to rock strength, most metallic ore deposits do not allow mechanical extraction methods, making necessary the use of drill and blasting, therefore, impeding continuous operation.

Traditional mining methods combining drill and blasting, excavators for loading and mobile equipment for hauling (or LHD for loading and hauling, in underground mining), have high levels of operational inefficiency and low equipment utilization: significant hauling cycles, in which at least half of the time the mobile equipment is empty, along with queues and waiting times at loading and dumping site, are some of the inefficiencies of these processes.

As discussed in the previous sections, increasing productivity and enhancing efficiency of operations are the main drivers for innovation. Then, the development of continuous extraction and material handling systems, outside the coal sector, are trends that will likely gain importance in the future.

Indeed, efforts in this matter have already been done in recent years. One example is the S11D iron mine of Vale in Brazil. This mine operates in four independent truckless systems. Each system consists of an excavator, a mobile sizer rig
(MSR), and a mobile belt wagon (MBW) that connects to a belt conveyor $(\mathrm{BC})$. Due to its continuous truckless design, the project has reported high operating productivity rates (about four times higher than Vale's typical rates in the region) and lower operating costs (approximately three times lower than Vale's traditional cost levels in the region) [54].

Initiatives in underground mining have also been developed. Such is the case of the Continuous Mining System (CMS) for caving operations, introduced by Codelco in Chile. This design considered the continuous and simultaneous extraction of broken ore from active drawpoints in a block or panel caving mine, by the combined action of feeders (located at the drawpoints), heavy weight conveyors, and primary crushers [55].

After almost 20 years of research and testing, the project was finally dismissed as a consequence of difficulties faced in the construction phase for its industrial validation [56]. Thus, the design did not get to be tested at an industrial level, and therefore, its real potential and applicability remained unclear. However, previous tests and studies suggested that great benefits in terms of productivity, costs, workforce requirements, and ramp-up duration can be achieved through the implementation of the CMS [57].

\section{Case Study: a Continuous Mining System for Caving Operations}

The Continuous Mining System (CMS) was an innovation project developed by Codelco, in Chile, that intended to create a continuous material handling system for block and panel caving operations. With the objective of illustrating the impacts and implications of implementing a disruptive innovation project, the CMS initiative is below described and analyzed.

\subsection{Codelco}

Codelco is a Chilean state-owned mining company, first copper and second molybdenum worldwide producer. It is divided into eight operating divisions located in the central and north of Chile. In total, Codelco possesses seven mining operations, four smelters and three refineries [58].

Divisions Andina, El Teniente, and Salvador include panel caving operations, thus the importance of projects such as CSM for the corporation. Moreover, Chuquicamata Underground Mine has been recently commissioned, a block caving operation that required over US\$ 5.5 billion for its construction and will extend the life of Chuquicamata Division for at least 40 years. $^{3}$

\footnotetext{
${ }^{3}$ Information available in https://www.codelco.com/
} 


\subsection{General Description of the Project}

The concept of continuous mining for caving operations was first introduced by Codelco and its Institute for Innovation in Mining and Metallurgy, IM2, in 1998. It was conceived as a tool to face the future challenges of underground mining, specifically the necessity of increasing extraction rates and improving safety [59].

This mining design was based on the following key elements $[59,60]$ :

- Application of preconditioning to ensure a proper fragmentation of the rock mass and an uneventful flow of broken ore through drawpoints

- Continuous and simultaneous extraction from active drawpoints by dozer feeders, increasing extraction rate and utilization

- Continuous transport of material by panzers

- Early size reduction of ore by sizer crushers

- Remote operation of the system, reducing the exposition of workers, and increasing productivity

The CMS comprised dozer feeders at the drawpoints, panzers to collect and transport the broken ore from the dozers to the sizer crushers, and finally the sizers themselves. Changing the operation of LHDs for a continuous material handling system also requires a reorganization of the layout of the extraction level. The basic differences between the El Teniente layout (typically used by Codelco in its caving operations) and the CMS layout are presented in Fig. 9.
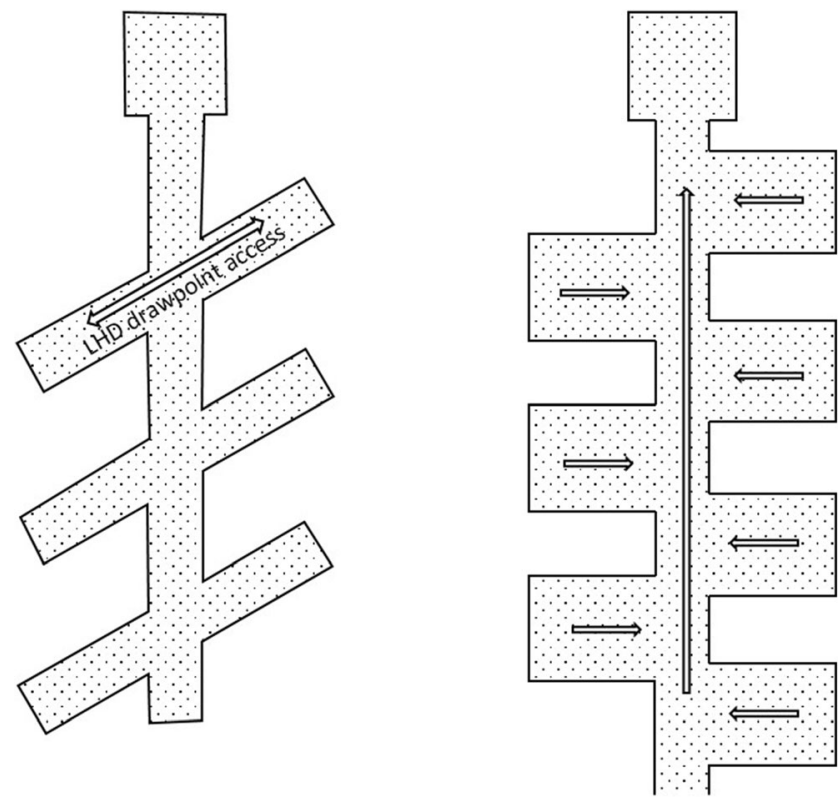

Fig. 9 El Teniente layout (left) vs. CMS layout (right). Modified after [57]. Left layout dedicated to LHD access to drawpoints, whereas right layout with perpendicular arrangement dedicated to continuous material flow with panzers (flow direction indicated by arrows)

\subsection{Process Validation of CMS}

After years of research since the concept was first introduced in 1998, the process validation for the CMS design was carried out in three phases.

\subsubsection{Phase I (2005): Dozer Feeder}

The first phase took place in Codelco's Salvador Mine, in 2005. It was focused on the validation at a pilot level of the concept of continuous extraction. For this, the extraction of ore from one drawpoint by a prototype of a dozer feeder was tested.

The test showed the capacity of the dozer feeder to extract the ore from the drawpoint at a reasonable rate $(200 \mathrm{t} / \mathrm{h}$ on average), allowing a proper flow within the ore column [55]. With these positive results, the process validation moved forward to Phase II.

\subsubsection{Phase II (2006-2008): Module CMS}

The second phase in the process validation of CMS was also executed in Salvador Mine. This time, a prototype of a modular system of continuous extraction, haulage, and crushing was tested. The module considered one haulage drift with four drawpoints, each one of them with a dozer feeding the panzer, which transported the ore to a roller impact crusher [57]. The module was built between 2006 and 2007 and the test itself carried out between 2007 and 2008. During this period, approximately $200,000 \mathrm{t}$ were extracted in total. The results achieved in Phase II were satisfactory, in terms of the performance of the different equipment and their interaction, though the roller impact crusher was dismissed for further tests due to its low availability and high components wear. In its place, a sizer crusher was incorporated afterwards [60].

\subsubsection{Phase III (2012-2016): Industrial Validation of CMS}

Due to the promising results in previous phases of validation, the company decided to move forward to Phase III, to validate at an industrial level the CMS method. This test aimed to evaluate the performance of the CMS method under real operating conditions, in Andina Division of Codelco. The design considered a sector of four haulage drifts (equipped with panzers) and eight drawpoints per drift (each one of them equipped with a dozer feeder), and a total test period of 38 months [57].

Phase III was defined as the validation test of CMS for its application in the Chuquicamata Underground Mine Project, which commissioning was planned for the first semester of 2019. In this sense, the main expected benefits from its applicability in the Chuquicamata Underground Mine originally were [57]: 
- Instant production rate: $3 \mathrm{t} / \mathrm{m}^{2}$-day

- OPEX: $20 \%$ lower

- Workforce requirements: $30 \%$ lower

- Ramp-up period: $25 \%$ shorter

- Improvements in safety and energy efficiency

- Net present value for its application in Chuquicamata: US\$ 1000 million

The construction of the test module started in 2012 . However, due to significant deviations in the execution period and budget, the works were stopped in December 2015. After more than 2 years of being paralyzed, and in the light of new studies and re-evaluations performed by Codelco, the project was finally cancelled in 2018 , totaling US\$ 138.1 million of loss [56].

\subsection{Analysis and Discussion}

From Codelco's experience in the process validation of the CMS innovation project, several key elements can be identified, and lessons can be learned:

\subsubsection{Time required for Process Validation}

Developing an innovation project for a technological breakthrough often requires long periods of time. Since the idea is conceived, conceptual studies must be carried out before initiating pilot and industrial validation tests. In the case of Codelco's CMS, over 20 years passed since the concept was first introduced until the industrial validation project was finally cancelled. During this time, other technologies are developed, which can be incorporated in the innovation project being tested, changing its potential value and future impact of its application. Specifically, during the process validation of CMS, significant advances were made in preconditioning techniques and digital technologies (e.g., automation, robotics). The project team must evaluate the impacts of new technologies developed along the way and incorporate them in the project if they prove to add value.

\subsubsection{CAPEX and Execution Period Estimation}

Process validation can be expensive, especially the industrial validation phase. Special care must be taken in the economic evaluation that justified the project and in the execution time and budget estimation. CMS project was stopped and finally cancelled due to problems in its construction phase, not because of unsatisfactory results of the test itself: this did not even get to be executed (similarly, also the first Epiroc Mobile Miner-back then Atlas Copco-was initially not accepted for prototype testing by the foreseen mine site [61]).

\subsubsection{Infrastructure Required and Coordination with the Operation}

New designs for extraction and material handling methods must be proved under real conditions for their industrial validation. For this, first the company needs to have access to ongoing mining operations, of its own property or coordinate with another company, in other cases. Then, a proper coordination with the current operation must be conducted, to minimize interferences and ensure the availability of resources (e.g., energy, water).

It is important to highlight the relevance of the CMS project, regarding its potential to improve extraction rates and safety in caving operations. Material handling systems through batch operations, such as the use of trucks and LHDs, are highly inefficient, from a macro point of view. Equipment show low levels of utilization and the productivity of the overall operation remains restricted. The design proposed by the CMS initiative offered the possibility of achieving higher production levels with lower requirements of active area, reducing CAPEX and OPEX, and gaining future dividends of the project earlier in time. All these factors have a positive effect on the economic indicators of a mining project: net present value increases and payback period is reduced, for example.

Finally, continuous mining and automated operations are trends that will likely shape the mining of the future. Initiatives like the CMS design should not be immediately dismissed, especially considering that this particular project failed in the construction stage of its industrial validation phase, having no chance to prove its applicability (or inapplicability) in a real operation.

\section{Conclusions}

Innovation plays an important role in the mining industry as a tool to improve the efficiency of its processes, reduce costs, but also to meet the increasing social and environmental concerns among communities and authorities. Technological progress has also been crucial to allow the exploitation of new deposits in more complex scenarios: lower ore grades, extreme weather conditions, deeper deposits, harder rock mass, and high-stress environments.

That is, the importance of innovation for the mining industry, as a critical factor in the improvement of labor productivity through past decades, was analyzed. Though its relevance, mining companies usually show low levels of R\&D intensity, similar to mature industries and far from high-tech sectors. The tendency to vertical disintegration has led firms to focus on their core business, relying mainly on equipment manufacturers and suppliers for the development of innovative solutions. Also, collaborative alliances between mining 
companies, suppliers, and research centers share a significant participation in the development of new technologies.

Nowadays, several technological trends can be identified as main factors that will shape the mining of the future. The first and most relevant one is the digital transformation (DT), as the process of adoption and incorporation of a set of tools, the so-called technologies 4.0, into the mining business. Automation, robotics, remotization of operations, internet of things, analytics, and digital twinning, among others, have the potential to enhance processes along the whole value chain of mining. However, though DT is frequently mentioned as one of the main concerns among most large-scale mining companies, the level of digitization of the industry remains low, indicating that most of the potential of DT for the sector is still to be unlocked. The main challenges that firms must face to achieve a successful digitization are the commitment and joint-task coordination between the different business units, implementing proper organizational structure changes, and promoting a new cultural mindset regarding cybersecurity strategies and their continuous improvement.

Other important trends are electromobility, invisible zerowaste mining, and continuous mining. These concepts answer the necessity of building a more sustainable and efficient industry, reducing the environmental footprint, and enhancing safety of mining operations. The replacement of fossil fuel-powered vehicles is a "must" in a world moving away from such energy sources to cleaner ones, and stricter safety and environmental regulations being implemented all around the world are a reflection of that. Every day more companies are evaluating the incorporation of electric-powered fleets into their operations, as existing technologies can already offer economic alternatives, while R\&D keeps advancing in this matter.

Invisible mining strategies, such as in situ leaching methods, have minimal impact on the surface and surroundings, and generate practically no waste. Yet, for a widespread application of this mining method, progress must be made in rock mass permeability enhancement (e.g. preconditioning techniques) and hydrogeological management, to ensure an optimal leaching process, in the first case, and minimize risks associated with groundwater pollution, in the second one.

Finally, though the concept of continuous mining has been applied for many years in the coal mining industry, its application in other mineral sectors has the potential to increase productivity, reduce costs, and improve safety, along with technological tools brought by DT, such as automation, robotics, and remotization of operations.

Funding Information Open access funding provided by Montanuniversität Leoben.

\section{Compliance with Ethical Standards}

Conflict of Interest The authors declare that they have no conflict of interest.
Open Access This article is licensed under a Creative Commons Attribution 4.0 International License, which permits use, sharing, adaptation, distribution and reproduction in any medium or format, as long as you give appropriate credit to the original author(s) and the source, provide a link to the Creative Commons licence, and indicate if changes were made. The images or other third party material in this article are included in the article's Creative Commons licence, unless indicated otherwise in a credit line to the material. If material is not included in the article's Creative Commons licence and your intended use is not permitted by statutory regulation or exceeds the permitted use, you will need to obtain permission directly from the copyright holder. To view a copy of this licence, visit http://creativecommons.org/licenses/by/4.0/.

\section{References}

1. Bartos PJ (2007) Is mining a high-tech industry? Resources Policy 32(4):149-158

2. Cambridge Dictionary. INNOVATION $\mid$ meaning in the Cambridge English Dictionary. https://dictionary.cambridge.org/ dictionary/english/innovation. Accessed 7 Jan 2020

3. Jara JJ, Pérez P, Villalobos P (2010) Good deposits are not enough: mining labor productivity analysis in the copper industry in Chile and Peru 1992-2009. Resources Policy 35(4):247-256

4. Fernandez V (2018) Copper mining in Chile and its regional employment linkages. Resources Policy

5. Tilton JE, Landsberg HH (1999) Innovation, productivity growth, and the survival of the US copper industry. Productivity in Natural Resource Industries:109-139

6. Aydin H, Tilton JE (2000) Mineral endowment, labor productivity, and comparative advantage in mining. Resource and Energy Economics 22(4):281-293

7. Garcia P, Knights PF, Tilton JE (2001) Labor productivity and comparative advantage in mining: the copper industry in Chile. Resources Policy 27(2):97-105

8. Upstill G, Hall P (2006) Innovation in the minerals industry: Australia in a global context. Resources Policy 31(3):137-145

9. Filippou D, King MG (2011) R\&D prospects in the mining and metals industry. Resources Policy 36(3):276-284

10. OECD (2017) OECD Science, Technology and Industry Scoreboard 2017: OECD

11. Pietrobelli C, Marin A, Olivari J (2018) Innovation in mining value chains: new evidence from Latin America. Resources Policy 58:110

12. Stubrin L (2017) Innovation, learning and competence building in the mining industry. The case of knowledge intensive mining suppliers (KIMS) in Chile. Resources Policy 54:167-175

13. Alta Ley. El Programa de Proveedores de Clase Mundial (PPCM). https://corporacionaltaley.cl/noticias/el-programa-de-proveedoresde-clase-mundial-ppcm/. Accessed 10 May 2019.

14. AUSTMINE (2015) New realities, bigger horizons. Australian Mining Equipment, Technology and Services (METS) National Survey

15. COCHILCO (2019) Encuesta de Innovación en Empresas Proveedoras de la Gran Minería. Santiago, Chile

16. Lasi H, Fettke P, Kemper H-G, Feld T, Hoffmann M (2014) Industry 4.0. Business \& Information Systems Engineering 6(4): 239-242

17. Rüßmann M, Lorenz M, Gerbert P, Waldner M, Justus J, Engel $P$ et al (2015) Industry 4.0: The future of productivity and growth in manufacturing industries. Boston Consulting Group 9(1):54-89 
18. Vial G (2019) Understanding digital transformation: a review and a research agenda. The Journal of Strategic Information Systems 28: $118-144$

19. Coombs D, O'Donnell C, Sparks J, Veiga P, Jones B (2019) Perspectives and opportunities in the mining equipment and services sector. Santiago, Chile

20. Deloitte (2017) The digital mine. What does it mean for you? Kalgoorlie, Australia

21. Bonomelli A (2018) Estrategia Digital Codelco. Santiago, Chile

22. Canart G (2018) Mining in the Digital Era. Aachen, Germany

23. Espinoza J (2018) Transformación Digital en Minería: la Clave de la Productividad Sustentable. Santiago, Chile

24. Romano V (2018) Mining 4.0: maximizing the potential as a premium, predictable company. Aachen, Germany

25. Sganzerla C, Seixas C, Conti A (2016) Disruptive innovation in digital mining. Procedia Engineering 138:64-71

26. World Economic Forum, Accenture. Digital Transformation Initiative: mining and Metals Industry; 2017.

27. Pino O (2018) Programa de Habilitación Tecnológica/ Transformación Digital. Santiago, Chile

28. Mosqueira R (2019) Autonomía Open Pit. Santiago, Chile

29. Canelo A (2018) 10 Años de Operación Autónoma en División Gabriela Mistral. Codelco. Presente y Futuro, Santiago, Chile

30. GlobalData (2020) Development of autonomous trucks in the global mining sector

31. Jeschke S, Brecher C, Meisen T, Özdemir D, Eschert T (2017) Industrial internet of things and cyber manufacturing systems. In: Industrial Internet of Things: Springer; 3-19

32. Carranza EJM, Laborte AG (2015) Random forest predictive modeling of mineral prospectivity with small number of prospects and data with missing values in Abra (Philippines). Computers \& Geosciences 74:60-70

33. Chen Y, Wu W (2017) Mapping mineral prospectivity using an extreme learning machine regression. Ore Geology Reviews 80: 200-213

34. Rodriguez-Galiano V, Sanchez-Castillo M, Chica-Olmo M, ChicaRivas M (2015) Machine learning predictive models for mineral prospectivity: an evaluation of neural networks, random forest, regression trees and support vector machines. Ore Geology Reviews 71:804-818

35. Manyika J (2017) What's now and next in analytics, AI, and automation

36. Autonomous vehicles, electrification and automation with a focus on people. https://www.1kab.com/en/news-room/news/ sjalvkorande-fordon-elektrifiering-och-automation-medmanniskan-i-centrum/. Accessed 8 Jun 2020.

37. International Mining. Resolute Mining starting to deliver automation benefits at Syama Underground - International Mining. https:// im-mining.com/2019/07/30/resolute-mining-starting-deliverautomation-benefits-syama-underground/. Accessed 8 Jun 2020.

38. Resolute Mining. Syama - Project overview. https://www.rml.com. au/syama/. Accessed 8 Jun 2020.

39. Gustafson A (2011) Automation of load haul dump machines: Luleå tekniska universitet

40. Parada S (2018) Innovación en Minería - EXPOMIN 2018. Santiago, Chile

41. EY (2018) Los 10 principales riesgos de la industria minera 20192020

42. Consejo de Competencias Mineras (2018) Impacto de las nuevas tecnologías en las competencias requeridas por la industria minera. Santiago, Chile
43. Erdtmann B (2018) Productivity and safety enhancement with Siemens solutions for non-hazardous underground mines. Aachen, Germany

44. Varaschin J, de Souza E (2015) Economics of diesel fleet replacement by electric mining equipment. In: 15 th North American Mine Ventilation Symposium

45. Paraszczak J, Svedlund E, Fytas K, Laflamme M (2014) Electrification of loaders and trucks-a step towards more sustainable underground mining. In: Proceedings of the International Conference on Renewable Energies and Power Quality (ICREPQ'14). Cordoba, Spain; 7-10

46. Valicek P, Fourie F (2014) Fuel cell technology in underground mining. In: The 6th International Platinum Conference,'PlatinumMetal for the Future', The SouthernAfrican Institute of Mining and Metallurgy; 325-332

47. Epiroc. Zero emission Epiroc. https://www.epiroc.com/en-za/ innovation-and-technology/zero-emission. Accessed 8 Jun 2020.

48. Mining Technology. In charge: the battery technologies leading the way in mining. https://www.mining-technology.com/features/incharge-the-battery-technologies-leading-the-way-in-mining/. Accessed 8 Jun 2020.

49. International Mining. Sandvik's electric LHDs stepping up including new battery-assisted LH514BE model - International Mining. https://im-mining.com/2020/02/10/sandviks-electric-lhdsstepping-including-new-battery-assisted-lh514be-model/. Accessed 8 Jun 2020.

50. Seredkin M, Zabolotsky A, Jeffress G (2016) In situ recovery, an alternative to conventional methods of mining: exploration, resource estimation, environmental issues, project evaluation and economics. Ore Geology Reviews 79:500-514

51. Sinclair L, Thompson J (2015) In situ leaching of copper: challenges and future prospects. Hydrometallurgy 157:306-324

52. Schlueter R, Mischo H (2018) In-situ bioleaching in crystalline rockformations: comparison of conditioning methods for enhanced permeability. In: SME Annual Meeting

53. Batterham RJ (2017) The mine of the future-even more sustainable. Minerals Engineering 107:2-7

54. Scheepers E (2018) Vale's S11D Project. Aachen, Germany

55. Orellana LF, Castro R, Hekmat A, Arancibia E (2017) Productivity of a continuous mining system for block caving mines. Rock Mechanics and Rock Engineering 50(3):657-663

56. Codelco (2018) Memoria Anual 2018

57. Baraqui J (2014) Minería Continua: El Futuro de la Minería Subterránea. Santiago, Chile.

58. Codelco (2018) Investor Update October 2018. Santiago, Chile

59. Carrasco F, Encina V, Le-Féaux R (2004) Continuous mining for caving method. In: Proceedings of MassMin 2004 Conference; 79 82

60. Orellana LF (2012) Evaluación de variables de diseño del sistema de minería continua a partir de experimentación en laboratorio. Master in Mining, Santiago

61. Ramström M. Mining Industry Game Changer: Atlas Copco News. http://www.atlascopco.com.au/auus/news/companynews/amining-industry-game-change.aspx. Accessed 25 Dec 2016.

Publisher's Note Springer Nature remains neutral with regard to jurisdictional claims in published maps and institutional affiliations. 